
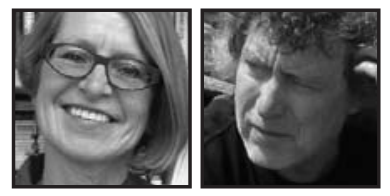

\title{
Commentary:
}

\section{Call and Response: The Importance of "Telling Truth Slant"}

\author{
Ardra L. Cole \& J. Gary Knowles
}

\section{ABSTRACT}

Funding agencies are restructuring programs, rewriting priorities, and restating accountability demands all founded on the very basic point that research funded by public tax dollars must be relevant and accountable to diverse publics. This new wave of accountability challenges researchers to "translate" and "mobilize" knowledge so that research is understood by those publics and makes a difference in people's lives. While goals of research accessibility are laudable, we argue that researchers' goals need not be focused on finding better ways to translate knowledge for public consumption. Rather, the time has come for inquiry to be more about actively engaging people in meaning making. As a community of researchers with long-standing commitment to using the arts in research as a vehicle for engagement, this is an opportunity for us to provide leadership in this area.

$\mathrm{n}$ his book A Hidden Wholeness: The Journey Toward an Undivided Life, Parker Palmer (2004) writes of the need to approach and explore important topics metaphorically through art. Art forms such as poetry, story, music, visual art, he says, embody the depth and complexity of important issues by creating "third things" with voices of their own "that tell the truth about a topic but, in the manner of metaphors, tell it on the slant" (p. 93). "Telling truth slant" is, itself, a metaphor taken from a poem by Emily Dickinson (1955). Palmer uses the poetic phrase as a reminder that "truth," neither definitive nor conclusive, cannot be proffered in an objective telling. Rather, "Truth evolves within us, between us, and around us as we participate 
in the "eternal conversation'"' (p. 128). "Mediated by a third thing," says Palmer, "truth can emerge from, and return to, our awareness at whatever pace and depth we are able to handle-sometimes inwardly in silence, sometimes aloud in community" (p. 93).

The many and diverse perspectives on the concept and meaning of truth, and how, even whether, a search for truth defines academic research continues to be debated vigorously in scholarly contexts, especially within the social sciences. These differences in epistemological perspective are reflected in a vast array of methodological approaches and practices. Dominant among them, still, are research methodologies based on assumptions and goals directed at finding and delivering answers and outcomes on complex issues and problems. Telling truth straight up, not slant, is the goal that typically defines researchers' work. Perhaps, though, the time has come for inquiry to be more about: asking questions than delivering answers, creating spaces for reflection and conversation rather than filling spaces with conclusions and exclusive, definitive answers, actively engaging people in meaning making rather than telling them what to think or do or be. Perhaps those of us who have been advocating and practicing these approaches for years now have an opportunity to show leadership in response to recent admonitions for the academy to be more relevant to its publics. ${ }^{1}$

Funding agencies, within Canada at least, are restructuring funding programs, rewriting research priorities, and restating accountability demands all founded on the very basic point that research funded by public tax dollars must matter to those publics, must be "translated"2 so that it is understood by those publics, and must show its potential to make a difference in people's lives. These are laudable goals; admittedly more readily accepted in some institutions than others, more easily achieved in some disciplines than others, more openly embraced by some researchers than others. Regardless, the point is that, echoes of Renaud's call to "get public or perish" have been made, heard, and are being answered. For those of us, who, for decades, have preached, practiced, and professed alternative ways of researching, this is good news.

This is our time to show and tell what "going public with research" could and does look like. It is our time to describe and demonstrate what happens when a broad goal of research is to connect with people and make a difference in their lives, to create spaces within which truth telling on the slant can take place, where metaphorical forms invite viewers, listeners, readers to gain insights into deep questions and issues through metaphorical third voices. 
In the early 1990s, a community of educational researchers formed in North America inspired and fueled by the work and words of the likes of Elliot Eisner and Maxine Greene, among others. Our common goal was to shift educational research away from a focus on the creation of propositional knowledge and toward representations of forms of understanding that came closer to the sentience and complexity of human experience. And, to varying degrees, we also wanted to make research more accessible to people outside of academic contexts. Our means of doing this was by bringing together methods and forms of researching and processes and representational forms of the arts. As happens in communities of creative thinkers and writers, different interpretations of the art-research relationship led to a number of iterations such as arts-based research, arts-informed research, a/r/tography, autoethnography, ethnodrama, lyric inquiry, and so on (see Handbook of the Arts in Qualitative Research: Perspectives, Methodologies, Examples, and Issues [Knowles \& Cole, 2008]). Since those early days the community of researchers infusing research with art has burgeoned.

Almost 20 years later we now hear the calls of funding agencies to make research more directly meaningful and relevant to the public, to make research matter. These are the very goals we have worked towards. And so it is with excitement and new challenge that we can heed these calls. But, in heeding these calls, we must be clear that we are not interested in "translating" knowledge, dumbing it down, putting it in "lay" terms, preparing easily digestible sound bytes-all different ways of passing on knowledge created in the academy for various publics and public consumption. What we are interested in is creating new research spaces, spaces that will invite engagement-sometimes private and introspective, other times public and interactive- - "about things that matter, conducted with passion and discipline" (Palmer, 2004, p. 127).

Whether through poetry, literary prose, two- or three-dimensional visual art, dramatic performance, music, film or digital media, we can show how our goals as researchers need not be to translate knowledge for public consumption but rather to engage publics in the act of knowledge creation. Poetry readings about poverty and homelessness, multi-media installations about caregiving and Alzheimer's disease, novels aimed to re-engage disenchanted youth, photography exhibits about people's relationships with animals, documentary films about the sex trade and sex trade workers, dramatic performances enacting experiences of living with metastatic disease, painting exhibits depicting issues and realities of homophobia and racism; these research-based representations have the power to do more to invite public engagement and transformative action than any number of sound bytes of "translated" research results. Moreover, readers, listeners, or viewers are more likely to come 
to understand inherent complexities of subject matter than to accept simplistic interpretations and solutions.

As we think about new learning and inquiry landscapes and the possibilities for the next phase in our development as researchers and as a research community, we need to continue to create these spaces and to show what it looks like to make research accessible, not by translating knowledge but by engaging people in meaning making, knowledge creation, interpretation, and truth telling ... slant. While this approach to inquiry requires a considerable shift for some, perhaps it is our responsibility, as a community of scholartists, ${ }^{3}$ to provide leadership in this area. We can continue to show how to create spaces, live questions, embrace silence, foster connections, so that the research work that we offer to the public is focused on inviting people to think deeply about issues and topics that matter to them. We can subvert the challenge to find more accessible, easier ways to pass on knowledge by creating spaces to invite engagement. We can show what happens when research becomes more democratic, and knowledge "production" becomes more epistemologically equitable; when researchers' responsibilities shift from telling, proving, and convincing to creating, inviting, and engaging. And, perhaps most important, we can continue to trust people to understand, make meaning, and take action.

Rather than looking to researchers for answers, people can use the tools researchers provide and spaces researchers create to find workable solutions to problems and issues that matter. No one person, no matter how well qualified, expert, experienced, methodical or eloquent, can offer definitive answers about complex social issues. "Truth," as Parker Palmer (2004, p. 127) says, "is an eternal conversation about things that matter, conducted with passion and discipline." Truths are personal and socially mediated. They "cannot possibly be found in the conclusions....because the conclusions keep changing."

We live in a time of urgency-a time when, as New York Times journalist, Thomas Friedmand, in an interview with a Microsoft researcher, put it, "The assumption now is that you are always in. Out is over.... And when you are always in you are always on" (cited in Kabat-Zinn, 2005, p. 158). Within contemporary academic contexts this urgency translates at all levels—students, faculty, administrators-to pressures to work harder and faster, to bring in larger amounts of funding, to produce more (not necessarily better), to be more competitive, to develop skills in areas such as communications technology that will enable a longer reach and more efficient management systems. The demands and pressures have increased so much that every time the productivity bar is raised or a new task is added to the list, it is 
presented as an "opportunity" in an attempt to disguise the reality that one more thing, one more challenge, task, or demand may be the proverbial straw. This is the reality within which researchers, educators, and scholars live and work. This is the context within which a "new wave of accountability" in research is demanded by funding agencies and public institutions.

As researchers we take on important issues, and we do our utmost to understand and represent truths. In order for research to have the kind of new wave accountability demanded, researchers must be enabled and encouraged to approach research in dramatically different ways, ways that engage people in spaces of trust to tell truth slant and make informed decisions that matter. Funding agencies now need to heed the response from the community of scholartists about what it means to translate knowledge and get public with research.

\section{Notes}

1. For an enlightening history and analysis of the origin and development of "the modern publics," link to CBC Ideas series, "The Origins of the Modern Publics, Parts 1-14" (http://www.cbc.ca/ideas/episodes/features/2010/04/26/the-originsof-the-modern-public/). Marc Renaud, President of the Social Sciences and Humanities Research Council of Canada 1998-2005, was known for his challenge to researchers to "get public or perish." This could be considered as the beginning of a new wave of research accountability.

2. The terms "knowledge mobilization" and "knowledge translation" are increasingly used by funding agencies and institutions to describe new priorities related to public accountability.

3. The term "scholartistry" was coined in 2000 by Lorri Neilsen to characterize the work of researchers who infuse their scholarship with artistry and artistic genres. 


\section{References}

Cayley, D. (2010, December 17), Producer, "The origins of the modern publics, parts 1-14," CBC Ideas. Retrieved May 2, 2011, from http://www.cbc.ca/ideas/episodes/fea tures/2010/04/26/the-origins-of-themodern-public/

Dickinson, E. (1955). In T. H. Johnson (Ed.). Complete poems of Emily Dickinson (Poem 1129). Boston: Back Bay Books.

Kabat-Zinn, J. (2005). Coming to our senses: Healing ourselves and the world through mindfulness. New York: Hyperion.
Knowles, J., G., \& Cole, A. L. (Eds.). (2008). Handbook of the arts in qualitative research: Perspectives, methodologies, examples, and issues. Thousand Oaks, CA: Sage Publishing.

Palmer, P. J. (2004). A hidden wholeness: The journey toward an undivided life. San Francisco: Jossey-Bass.

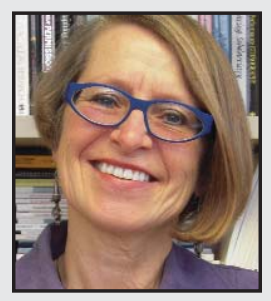

Ardra L. Cole is Associate Vice-President, Academic and Research, Mount Saint Vincent University, Halifax, Nova Scotia. As a teacher educator and qualitative research methodologist, and former Professor and Co-director, Centre for Artsinformed Research, OISE, University of Toronto, Ardra has published extensively in conventional and non-conventional academic prose and in alternative, scholarly, non-print media. Her research (with Maura McIntyre) on caregiving and Alzheimer's disease involves multi-media installation, performance, and the World Wide Web. Ardra's most recent venture is as Founder and Director of the not-for-profit organization, ElderDog Canada-an exciting new venture that honours older dogs and older adults and the special bond between them. 


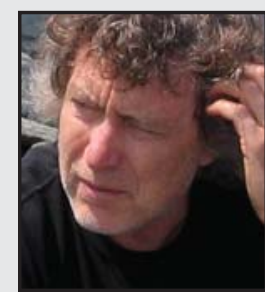

J. Gary Knowles is a visual artist, Professor of Creative Inquiry and Adult Learning, and Co-director of the Centre for Arts-informed Research, Ontario Institute for Studies in Education, University of Toronto. Co-editor of The Artsinformed Inquiry Series (Backalong Books) and Handbook of the Arts in Qualitative Research (Sage), Gary has helped numerous graduate degree candidates complete arts-informed doctoral and Master's degree theses employing poetic, fictional, performative, and visual arts inquiry processes and forms for addressing educational and social issues. Gary's educational scholarship is located in educational journals and books, as well as found hanging on walls.

LINK TO:

www.oise.utoronto.ca/research/mappingcare

www.utoronto.ca/CAIR 